\title{
EPICONDYLITIS AFTER TREATMENT WITH FLUOROQUINOLONE ANTIBIOTICS
}

\author{
J. C. Le HuEC, T. SChaeverbeke, D. ChauveauX, J. RIVEl, J. Dehais, A. Le Rebeller
}

From the University of Bordeaux, France

We report two cases of epicondylitis of the elbow occurring after treatment with fluoroquinolone antibiotics. Both patients had intense pain which appeared very shortly after the first dose of the drug and was not relieved by conservative treatment. Ultrasonography revealed extensive inflammatory lesions with pseudonecrotic areas. MRI confirmed the lesions and also showed a subclinical abnormality of the adjoining tendons. The persistent nature of the pain was the indication for surgical release of the extensor mechanism. After operation pain disappeared completely and the patients were able to return to their normal activities.

Lesions of the tendo Achillis are a well-known side-effect of treatment with fluoroquinolone. Our two cases show that such lesions may occur elsewhere. They also indicate the need for caution when prescribing these antibiotics to patients at risk of tendon lesions, such as top-level sportsmen or patients on dialysis or steroid treatment.

J Bone Joint Surg $\mid \mathrm{Br} /$ 1995:77-B:293-5.

Received 26 May 1994; Accepted 28 July 1994

Complications involving tendons are an uncommon but well-recognised problem associated with the fluoroquinolone group of antibiotics (McEwan and Davey 1988), occurring in about $0.02 \%$ of patients (Herait 1993). The tendo Achillis is usually affected, but other sites may be involved (Falt-Rolachon et al 1993; Tonolli-Serabian et al 1993). We describe two patients with epicondylitis after treatment with perfloxacin and ciprofloxacin, respectively.

J. C. Le Huec, MD. Orthopaedic Surgeon

D. Chauveaux. MD. Orthopaedic Surgeon

A. Le Rebeller. MD. Professor of Orthopaedic Surgery

T. Schaeverbeke, MD. Rheumatologist

J. Dehais. MD. Professor of Rheumatology

J. Rivel, MD. Anatomopathologist

University of Bordeaux II. Hôpital Pellegrin. 33076 Bordeaux Cedex. France.

Correspondence should be sent to Dr J. C. Le Huec.

(1)1995 British Editorial Society of Bone and Joint Surgery $03(01-620 \times / 95 / 2943 \$ 2.00)$

\section{CASE REPORTS}

Case 1. A 48-year-old man who was a keen squash player was given perfloxacin $800 \mathrm{mg} /$ day for orchitis. On the second day of treatment he developed generalised erythema, and on the next day had severe pain in the lateral epicondyle of his right elbow. On the fourth day a generalised bullous eruption appeared and the drug was stopped.

The skin disorder settled within ten days. but he continued to have pain at the elbow and could not play squash. At two months, ultrasonography showed an abnormality in the tendinous attachment to the lateral epicondyle (Fig. 1). Conservative treatment was unsuccessful and after ten months release of the extensor tendons was performed. An area of necrosis was seen in the tendon and histological examination of an excised specimen showed hyaline necrosis with associated peripheral giant cells. After operation the pain disappeared and the patient returned to playing squash.

Case 2. A 45-year-old man received ciprofloxacin $800 \mathrm{mg} /$ day for a bronchopulmonary infection. On the third day of treatment he felt a sharp pain in the right lateral epicondyle which hampered all lifting and grasping movements. He played pelota (a ball-throwing sport) for about an hour every week, and had not previously had problems with his elbow. Ultrasonography was performed 45 days after the onset of pain and indicated a lesion at the attachment of the extensor tendons. MRI after 90 days showed hyperintense signals at the epicondyle and in the triceps tendon in which fluctuating pain developed later (Fig. 2). Conservative treatment, including immobilisation for three weeks in a cast, was unsuccessful, and an extensor release was performed. Gross necrosis was not observed, but histological examination of the biopsy section showed similar features to those seen in case 1 . A full recovery was made.

\section{DISCUSSION}

Most tendon lesions thought to result from treatment with fluoroquinolone involve the tendo Achillis, but two patients have been reported with rupture of the supraspinatus tendon (Falt-Rolachon et al 1993; Tonolli-Serabian 1993) and one with rupture of the extensor pollicis longus (Chaslerie et al 1992). Jorgenson et al (1991) describe a lesion in a peroneus brevis tendon used to repair a torn tendo Achillis. 


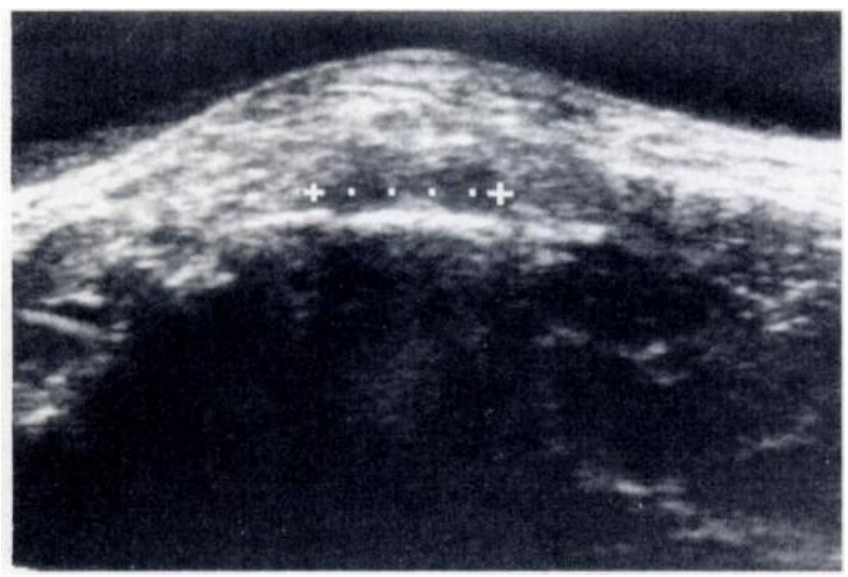

Fig. 1

Case 1. Two months after the onset of symptoms ultrasonography showed an area of possible necrosis in the tendon adjacent to the lateral epicondyle.

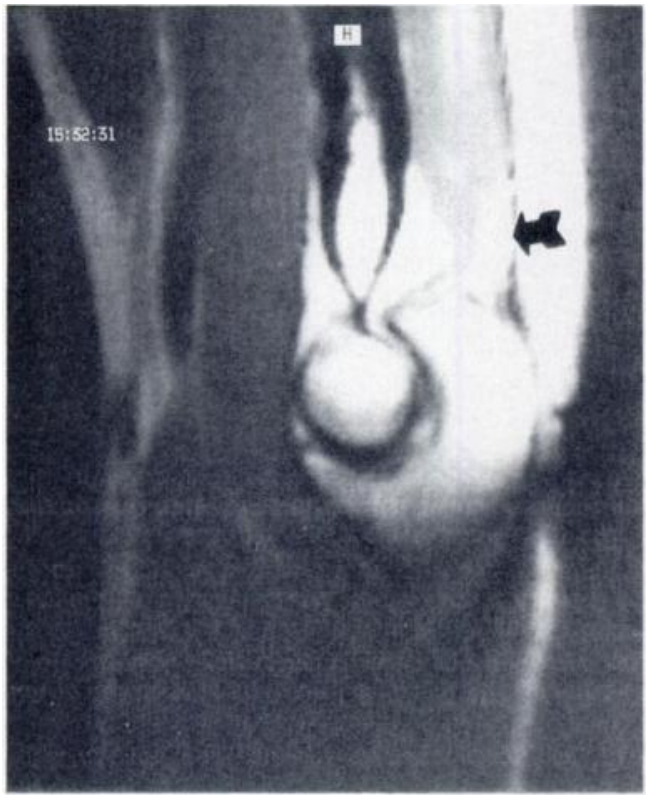

Fig. 2

Case 2. MRI performed 90 days after the onset of pain showed a hyperintense lesion on the T2-weighted image at the epicondyle and in the triceps tendon.

Koeger et al (1993) in a T2-weighted MRI study showed hyper-intense signals in the tendo Achillis and in the patellar and supraspinatus tendons in $40 \%$ of the patients after eight days of treatment with fluoroquinolone. In our case 2, MRI confirmed an abnormal signal in a T2-weighted sequence and this may prove to be useful in monitoring potential lesions. Ultrasonography was helpful in demonstrating abnormalities of the tendon in our patients.

In our patients, treatment with fluoroquinolone seemed to be the most probable cause of the tendon lesions. Although they both played sport neither had any other risk factors such as renal failure or corticosteroid therapy (Franck et al
1991: Chaslerie et al 1992; Ribard et al 1992; Borderie et al 1993).

The cause of these iatrogenic lesions of the tendons is unknown. The only pathological study in the literature reports necrosis with no inflammatory cell infiltrate or angiitis (Jorgensen et al 1991). In our first case histological examination showed a few macrophages and giant cells peripheral to the injured tendon (Fig. 3). The presence of giant cells usually indicates a reaction to a foreign body, so the meaning of this reaction is not clear. It seems possible that their presence showed that necrotic tissue had been absorbed, but giant cells are not usually found in association with such tissue.

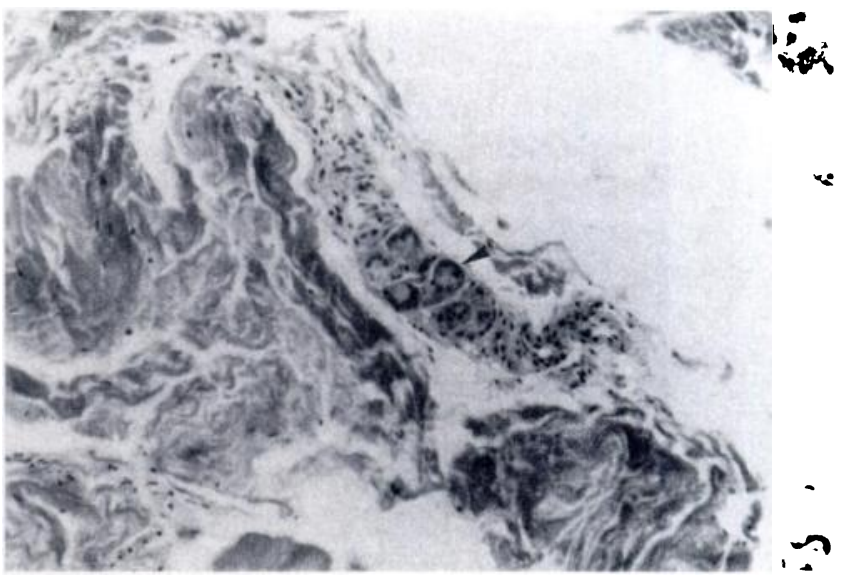

Fig. 3

Case 1. Histological examination showed peripheral giant cells but no evidence of necrosis (haematoxylin and eosin-safran $\times 200$ ).

Tendon is a connective-tissue structure with a low cell content, mainly fibroblasts, little vascularity, and is primarily composed of collagen fibres. There may be a direct toxic effect on the collagen. The sudden onset of some tenopathies, sometimes after a single dose of a quinolone, suggests the possibility of direct toxicity.

Fluoroquinolone-induced arthropathies seem to be more common in children (Pertuiset et al 1989; Ollier et al 1990; Chevalier et al 1992) and may have destructive and disabling effects. These antibiotics should be avoided in children. In growing dogs, identical types of arthropathy, with histological lesions of the deep layers of the joint cartilage, have been observed after first-generation quinolones; adult dogs never showed this type of lesion even at a very high dosage (Tatsumi et al 1978). Tendon lesions appear to occur only in adults. but it seems likely that some adult arthralgias occurring in association with the use of fluoroquinolones may be due to deep tendon lesions which are difficult to detect. MRI or ultrasonography may be helpful in making the diagnosis.

No benefits in any form have been received or will be received from a commercial party related directly or indirectly to the subject of this article. 


\section{REFERENCES}

Borderie P. Marcelli C. Leray $\mathbf{H}$, et al. Rôle des fluoroquinolones dans la survenue des ruptures du tendon d'Achille après transplantation rénale. In: Gaucher A. Neter P, Pourel J, Régent D, Mainard D, Gillet P. eds. Pharmacologie clinique inflammation imagerie ostéoarticulaire rhumatismes et infections indices de qualité de vie cartilage biomatériaux. Paris, etc: Masson. 1993:68-73.

Chaslerie A, Bannwarth B, Landreau JM, Yver L, Begaud B. Tendon rupture and fluoro-quinolones: an undesirable effect of drug selection. Rev. Rhum Mal Ostéoartic 1992:59:297-8.

Chevalier X, Albengres E, Tillement JP, Voisin MC, Larget-Piet B. A case of destructive polyarthropathy in a 17-year-old youth following pefloxacin treatment. Drug Saf 1992:7:310-4.

Falt-Rolachon I, Pireyre C, Rolachon A, et al. Rupture bilatérale de coiffe des rotateurs lors d'un traitement par ofloxacine: a propos d une observation. Rev Rhum Mal Ostéoartic 1993:60:752.

Franck JL, Bouteiller G, Chagnaud P, Sapene M, Gautier D. Achilles tendon rupture in 2 adults treated with pefloxacin: one of the cases with bilateral involvement. Rev Rhum Mal Ostéoartic 1991:58:904.

Herait P. Tendinopathies et fluoroquinolones: évaluer le rapport bénéfice/ risque et surveiller les sujets traités. Concours Med 1993;115:823-4.

Jorgensen C, Anaya JM, Didry C, et al. Arthropathy with Achilles tendon involvement induced by pefloxacin. Rev Rhum Mal Ostéoartic 1991:58:623-5
Koeger AC, Chaibi P, Roger B, et al. Apport de I'IRM dans les complications tendineuses des fluoroquinolones. Rev Rhum Mal Ostéoartic 1993:60:752.

McEwan SR, Davey PG. Ciprofloxacin and tenosynovitis. Lancet 1988; 2:900.

Ollier S, Laroche M, Arlet P, et al. Arthropathy caused by pefloxacin: report of a case. Rev Rhum Mal Osténartic 1990;57:671

Pertuiset E, Lenoir G, Jehanne $M$, et al. Joint tolerance of pefloxacin and ofloxacin in children and adults with cystic fibrosis. Rev Rhum Mal Ostéoartic 1989:56:735-40.

Ribard P, Audisio F, Kahn MF, et al. Seven Achilles tendinitis including 3 complicated by rupture during fluoroquinolone therapy. $J$ Rheumatol 1992;19:1479-81.

Tatsumi H, Senda H, Yatera S, et al. Toxicological studies on pipemidic acid. V. Effect on diarthrodial joints of experimental animals. J Toxicol Sci 1978:3:357-67.

Tonolli-Serabian I, Mattei JP, Poet JL, Trives M, Roux H. Rupture de la coiffe des rotateurs au cours d'un traitement par quinolone. In: Pélissier J. Simon L, Rodineau J, eds. Pathologie de la coiffe des rotateurs de l'épaule. Paris, etc: Masson. 1993:147-50. 